Tropical Journal of Pharmaceutical Research May 2016; 15 (5): 1003-1012

ISSN: 1596-5996 (print); 1596-9827 (electronic)

(C) Pharmacotherapy Group, Faculty of Pharmacy, University of Benin, Benin City, 300001 Nigeria.

All rights reserved.

Available online at http://www.tjpr.org

Original Research Article

http://dx.doi.org/10.4314/tjpr.v15i5.15

\title{
A novel method to determine new potent angiotensin inhibitor, azilsartan, in human plasma via micelle-enhanced spectrofluorimetry using cremophor RH 40
}

\author{
Hany W Darwish ${ }^{1,2 \star}$, Ahmed H Bakheit ${ }^{1}$, Ali S Abdelhameed ${ }^{1}$ and Bakheit \\ Mustafa ${ }^{3}$ \\ ${ }^{1}$ Department of Pharmaceutical Chemistry, College of Pharmacy, King Saud University, PO Box 2457 Riyadh, 11451, Kingdom \\ of Saudi Arabia, ${ }^{2}$ Analytical Chemistry Department, Faculty of Pharmacy, Cairo University, Kasr El-Aini St, Cairo 11562, Egypt, \\ ${ }^{3}$ El-Neelain University, Faculty of Science and Technology, Department of Chemistry, PO Box 12702, Khartoum, Sudan
}

*For correspondence: Email: hdarwish75@yahoo.com

Received: 17 February 2016

Revised accepted: 9 April 2016

\begin{abstract}
Purpose: To develop a micelle-enhanced spectrofluorimetric method for the assay of azilsartan (AZL) in bulk form and spiked human plasma without the need for derivatization procedure.

Method: The proposed method was based on studying the fluorescence behavior of AZL in Cremophor $\mathrm{RH} 40$ ( $\mathrm{Cr} \mathrm{RH} 40$ ) micellar system. The fluorescence intensity was measured at $371 \mathrm{~nm}$ after excitation at $264 \mathrm{~nm}$. The proposed procedure was validated according to International Council on Harmonization (ICH) guidelines.

Results: In aqueous solution, the fluorescence intensity of AZL was greatly enhanced by more than 3fold in the presence of $\mathrm{Cr} \mathrm{RH} 40$. The fluorescence-concentration plot was linear over the range of 10 $-500 \mathrm{ng} \cdot \mathrm{mL}^{-1}$, with a limit of detection of $3.287 \mathrm{ngmL}^{-1}$. The proposed method was successfully applied to the determination of AZL in pure powder form and spiked human plasma. The mean recovery of AZL in spiked human plasma using the proposed method was $90.54 \pm 1.17 \%$.

Conclusion: The suggested method is highly sensitive and simple, and can easily be applied for the quantification of AZL in pure powder form as well as in biological fluids such as plasma
\end{abstract}

Keywords: Azilsartan, Spectrofluorimetry, Spiked human plasma, Micellar system

Tropical Journal of Pharmaceutical Research is indexed by Science Citation Index (SciSearch), Scopus, International Pharmaceutical Abstract, Chemical Abstracts, Embase, Index Copernicus, EBSCO, African Index Medicus, JournalSeek, Journal Citation Reports/Science Edition, Directory of Open Access Journals (DOAJ), African Journal Online, Bioline International, Open-J-Gate and Pharmacy Abstracts

\section{INTRODUCTION}

Hypertension affects about 74.5 million individuals in the United States [1]. Despite the availability of antihypertensive agents, hypertension remains inadequately controlled, with slightly less than half of patients who receive medication successfully achieving adequate blood pressure (BP) [2]. While there are many drug classes available to reduce $\mathrm{BP}$, drugs that modulate the renin-angiotensin-aldosterone system (RAAS) are more commonly used because of their efficacy, in addition to their low side effects [3]. Within the RAAS classes, those that inhibit the action of angiotensin II by binding directly to the angiotensin type 1 (AT1) receptor (i.e. angiotensin receptor blockers [ARBs]) are the best tolerated of all antihypertensive drug classes [3].

Azilsartan medoxomil is a new ARB developed for management of hypertension. It is a prodrug that is rapidly hydrolyzed to its active moiety, azilsartan (AZL). Chemically, AZL is known as 2- 
Ethoxy-1-\{[2'-(5-oxo-2,5-dihydro-1,2,4-oxadiazol3-yl)-4-biphenylyl]methyl\}-1H-benzimidazole-7carboxylic acid. The US Food and Drug Administration (FDA) approved Edarbi® tablet (azilsartan medoxomil potassium) on February 25, 2011 to treat hypertension in adults [4]. It is available in $80 \mathrm{mg}$ and $40 \mathrm{mg}$ dosages with the recommended dose of $80 \mathrm{mg}$ daily. Spectrofluorimtric analysis is a very simple, highly sensitive and inexpensive technique that is available at almost all analytical laboratories. The sensitivity of spectrofluorimetry is enhanced by different ways including micellar enhanced approach.

Several micelle-enhanced spectrofluorimetric studies have been reported for the determination of various drugs [5-7]. This fact is due to the ability of the formed micelle to enhance the fluorescence intensity of the weakly fluorescent molecules. Moreover, these procedures represent sensitive and eco-friendly methodology as there is no need for organic solvents. Micellar enhanced analytical methods are relied on addition of surfactants such as sodium dodecyl sulphate (SDS) [7,8], Tween $[9,10]$ and cyclodextrin, etc $[11,12]$. Nevertheless, using non-ionic surfactant "Cremophor $\mathrm{RH} 40$ " is not familiar in the reported methods for determination of drugs. Cremophor $\mathrm{RH} 40$ is manufactured by reacting $40 \mathrm{~mol}$ of ethylene oxide with hydrogenated castor oil. It contains mainly the triricinoleate ester of ethoxylated glycerol, with smaller amounts of polyethylene glycol ricinoleate and the corresponding free glycols [13].

A thorough survey of the literature revealed that few reports were published recently for assaying AZL alone in dosage form using highperformance liquid chromatography (HPLC) [1416], UV spectrophotometry [17], highperformance thin layer chromatography (HPTLC) $[14,18]$ and in dog and human plasma using LC/MS $[19,20]$. AZL in combination with chlorthalidone was also determined in dosage form using UV and fluorescence spectrophotometry [21], HPLC [22-25] and in human and rat plasma using LC/MS [26]. Fluorescence spectrometry is a very simple, rapid, efficient, selective, and highly sensitive technique for determination of drug in plasma [27-29]. Therefore, the aim of the current study is to develop and validate a new sensitive, simple and rapid micelle-enhanced spectrofluorimetric method for the in vitro determination of AZL in spiked human plasma. The current procedure does not involve derivatization step due to the intrinsic fluorescent property of AZL.

\section{EXPERIMENTAL}

\section{Apparatus}

Fluorescence measurements were carried out on a fluorescence spectrometer (model FP-8200, Jasco Corporation, Japan) equipped with a 150 $\mathrm{W}$ xenon lamp and $1 \mathrm{~cm}$ quartz cells. The slit widths for both the excitation and emission monochromators were set at $5.0 \mathrm{~nm}$. The calibration and linearity of the instrument were frequently checked with standard quinine sulphate $(0.01 \mu \mathrm{g} / \mathrm{mL})$. Wavelength calibration was performed by measuring $\lambda_{\mathrm{ex}}$ at $275 \mathrm{~nm}$ and $\lambda_{\mathrm{em}}$ at $430 \mathrm{~nm}$; no variation in the wavelength was observed. All recorded spectra converted to ASCII format by SpectraManager ${ }^{\circledR}$ software. A Hanna $\mathrm{pH}$-Meter (Romania) was used for $\mathrm{pH}$ adjustments.

\section{Reagents and materials}

All the chemicals used were of analytical reagents grade, and the solvents were of HPLC grade. Azilsartan reference standard (purity, $99.6 \%$ was purchased from Weihua Pharma Co. Ltd (Zhejiang, China). Polyoxyl 40 hydrogenated castor oil (Cremophor RH40), Polyoxyl 35 hydrogenated castor oil (Cremophor EL) were purchased from BASF (Ludwigshafen, Germany) and used as $1 \% \mathrm{w} / \mathrm{v}$ aqueous solution for Cremophor EL and $1 \% \mathrm{v} / \mathrm{v}$ aqueous solution for Cremophor EL. Sodium dodecyl sulphate (SDS, $95 \%$ ) was purchased from Winlab (UK) and used as $1 \% \mathrm{w} / \mathrm{v}$ aqueous solution. $\beta-$ cyclodextrin ( $\beta-C D)$ and carboxymethylcellulose (CMC) were obtained from Merck (Germany) and used as $1 \% \mathrm{w} / \mathrm{v}$ aqueous solution. Tween-20, tween-80 and tween-85 (Techno Pharmchem Haryana Company (INDIA)), were used as $1 \%$ $\mathrm{v} / \mathrm{v}$ aqueous solution. Methanol, ethanol (Prolabo, France) and acetonitrile (Sigma-Aldrich Chemie $\mathrm{GmbH}$, Germany). Boric acid, sodium hydroxide, phosphoric acid, potassium chloride, potassium dihydrogen phosphate and disodium hydrogen phosphate were all of spectroscopic grade. Phosphate buffer $(0.1 \mathrm{M}, \mathrm{pH} 2-7)$, and borate buffer $(0.1 \mathrm{M}, \mathrm{pH} 8-10)$ solutions were freshly prepared. Ultrapure water of $18 \mu \Omega$ was obtained from a Millipore Milli- $Q^{\circledR}$ UF Plus purification system (Millipore, Bedford, MA, USA). Human plasma was kindly provided by King Khaled University Hospital (King Saud University, Riyadh, KSA). After informed consent was obtained, fasting blood samples were taken and plasma was separated and stored at $-70^{\circ} \mathrm{C}$. 


\section{Standard solutions}

AZL stock solution $\left(1 \mathrm{mgmL}^{-1}\right)$ was prepared by dissolving accurately measured amounts of AZL reference standard material in methanol. This solution was found to be stable for several weeks when kept in the refrigerator. A working standard of $20 \mathrm{\mu gmL}^{-1}$ was prepared daily by dilution of stock standard solution with methanol.

\section{Construction of the calibration graph}

Aliquots of AZL standard solution were transferred into a series of $5 \mathrm{~mL}$ volumetric flasks to give final concentrations of $10-500 \mathrm{ngmL}^{-1}$. A volume of $0.9 \mathrm{~mL}$ of Cremophor $\mathrm{RH} 40(\mathrm{Cr} \mathrm{RH}$ 40) was added followed by addition of $1 \mathrm{~mL}$ of phosphate buffer and diluted to the mark with distilled water. The contents of the flasks were mixed well and the relative fluorescence intensity (RFI) was measured at $371 \mathrm{~nm}$ after excitation at $264 \mathrm{~nm}$. RFI was plotted vs. nominal drug concentration $\left(\mathrm{ngmL}^{-1}\right)$ to obtain the calibration graph. The linear regression equation for the data was computed.

\section{Assay of human plasma samples}

Plasma samples were stored at $-20{ }^{\circ} \mathrm{C}$ and allowed to thaw at room temperature before processing. Twenty microliters of AZL standard solutions of different concentrations (3.2, 3.6, $4.8,5.4,6.0 \mu \mathrm{g} / \mathrm{mL}$ ) were spiked into $200 \mu \mathrm{L}$ of human plasma and mixed for $2 \mathrm{~min}$. A volume of $100 \mu \mathrm{L}$ of phosphate buffer $\mathrm{pH} 11$ was added and the solution was vortexed for 1 minute, the volume was then completed to $1.5 \mathrm{~mL}$ with methanol and vortexed for other 2 min followed by centrifugation for $20 \mathrm{~min}$ at $12000 \mathrm{rpm}$ at room temperature. The supernatant was then transferred and filtered through $0.2 \mu \mathrm{M}$ syringe filter into glass vials and dried under a gentle stream of nitrogen. Finally, the residues were reconstituted in $50 \mu \mathrm{L}$ methanol, $900 \mu \mathrm{L} \mathrm{Cr} \mathrm{RH}$ 40 and $1 \mathrm{~mL}$ phosphate buffer $(\mathrm{pH} 3.0)$ and volume was completed to $3 \mathrm{~mL}$ with water. A blank plasma sample was treated similarly. RFI was measured at $371 \mathrm{~nm}$ after excitation at 264 $\mathrm{nm}$ and the concentration of the drug was calculated from the corresponding regression equation.

\section{RESULTS}

Figure 1 shows the chemical structure of AZL. The fluorescence properties of AZL in both aqueous and $\mathrm{Cr} \mathrm{RH} 40$ systems were studied where AZL exhibited an emission band at 371 $\mathrm{nm}$ after excitation at $264 \mathrm{~nm}$. Figure 2 illustrates the fluorescence spectra of $A Z L$ in the two systems. The first system was aqueous system, while the second was the same aqueous system in the presence of $\mathrm{Cr} \mathrm{RH} 40$ as a fluorescence enhancer. The optimum conditions for fluorimetric estimation of AZL were established through number of experiments.

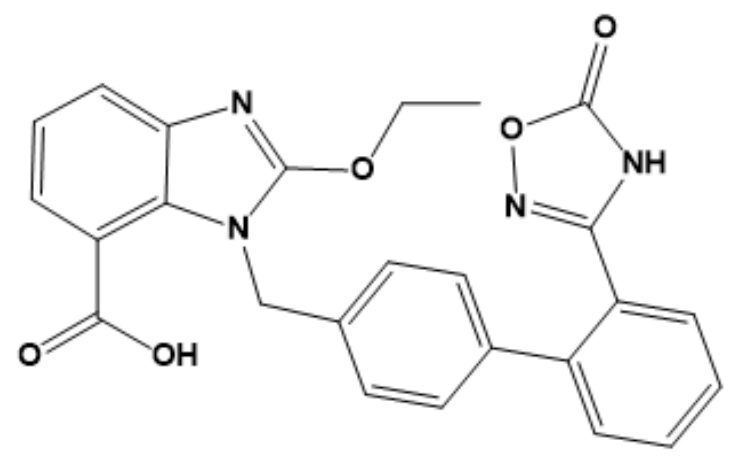

Figure 1: Chemical structure of Azilsartan (AZL)

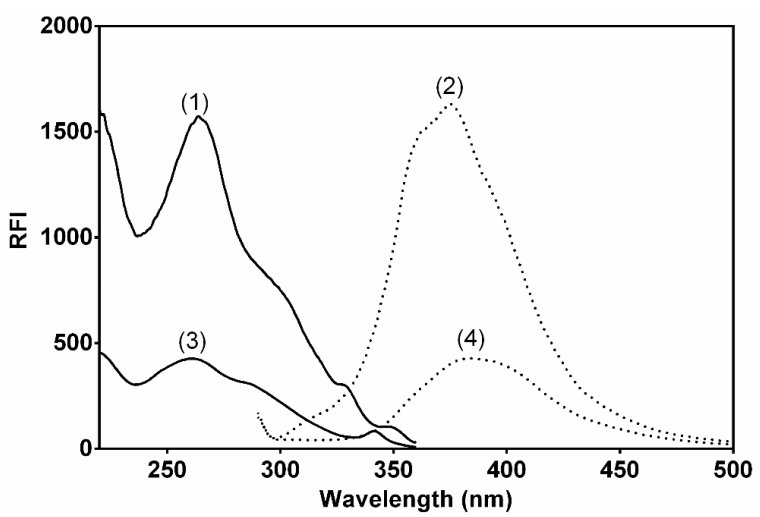

Figure 2: Excitation (1) and emission (2) spectra of AZL $\left(200 \mathrm{ngmL}^{-1}\right)$ in $\mathrm{Cr} \mathrm{RH} 40(1 \%, w / v)$; excitation (3) and emission (4) spectra of AZL (200 $\left.\mathrm{ngmL}^{-1}\right)$ in water

\section{Optimization of experimental conditions}

\section{Effect of organized media}

The effect of different organized media on the RFI of AZL was studied by adding $0.5 \mathrm{~mL}, 1 \%$ $\mathrm{w} / \mathrm{v}$ solution of each surfactant to the drug solution. Different surfactants, like sodium dodecyl sulfate (SDS) [anionic surfactant], Cremophor El, Cr RH 40, carboxymethylcellulose (CMC), tween 80 [nonionic surfactants] and macromolecules such as $\beta$-cyclodextrin were tried. The low critical micelle concentration $(\mathrm{cmc})$ values of nonionic surfactants render them better solubilizers for hydrophobic drugs compared to ionic surfactants [30]. As shown in figure 3 three nonionic surfactants, namely $\mathrm{Cr} \mathrm{RH} 40$, Cr EL and Tween 20, demonstrated high RFI results for AZL determination. 


\section{Effect of volume of nonionic surfactants}

The influence of $\mathrm{Cr} R \mathrm{HH} 40, \mathrm{Cr} E \mathrm{~L}$ and Tween 20, on the RFI of AZL was studied using different volumes of $1 \% \mathrm{w} / \mathrm{v}$ solutions. On increasing their volumes, $\mathrm{Cr} \mathrm{RH} 40$ showed the highest results (Fig 4). The RFI of AZL using $\mathrm{Cr} \mathrm{RH} 40$ increased significantly up to $800 \mu \mathrm{L}(1 \% \mathrm{w} / \mathrm{v})$, where after this volume no more significant increase in RFI was observed. Therefore, $900 \mu \mathrm{L}$ $1 \% \mathrm{w} / \mathrm{v} \mathrm{Cr} \mathrm{RH} 40$ solution was chosen for AZL determination.

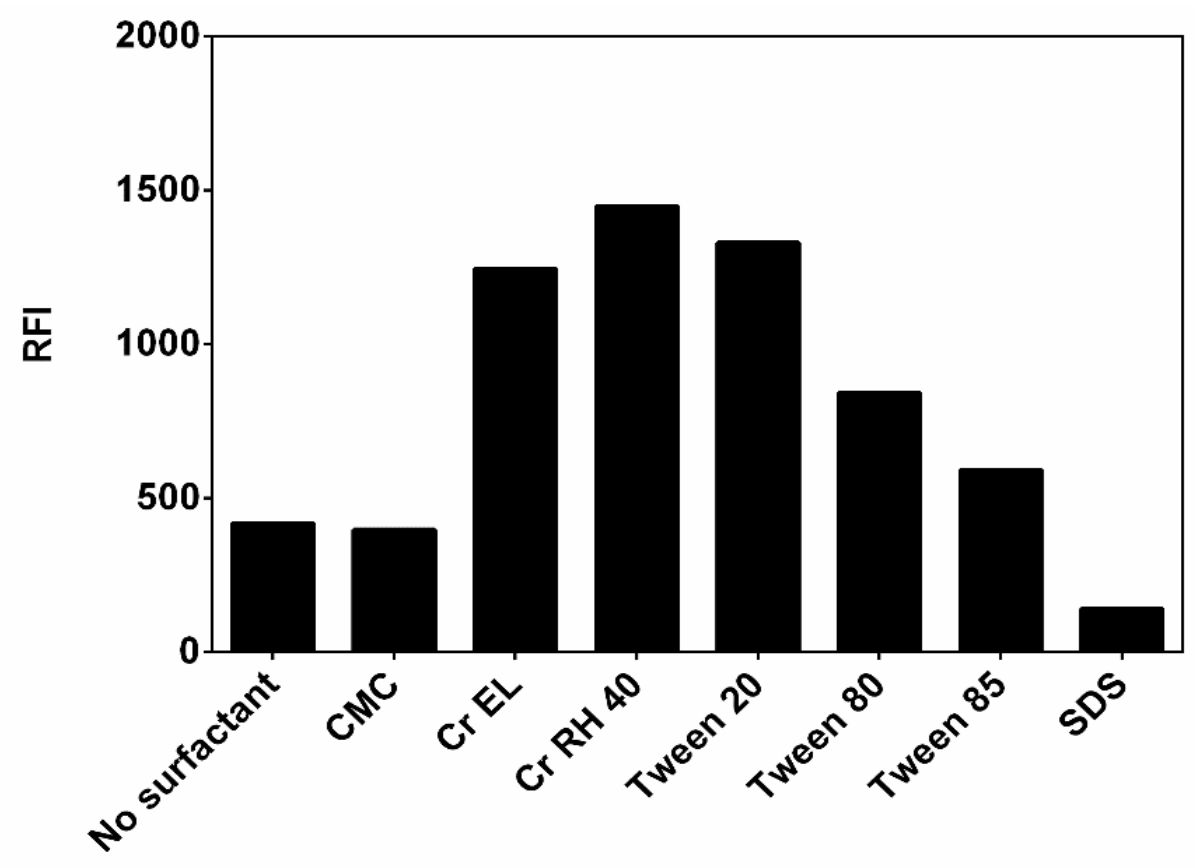

\section{Surfactant}

Figure 3: Effect of different organized media ( $0.5 \mathrm{~mL}, 1 \% \mathrm{w} / \mathrm{v}$ solution of each) on RFI of AZL ( $\left.200 \mathrm{ngmL}^{-1}\right)$

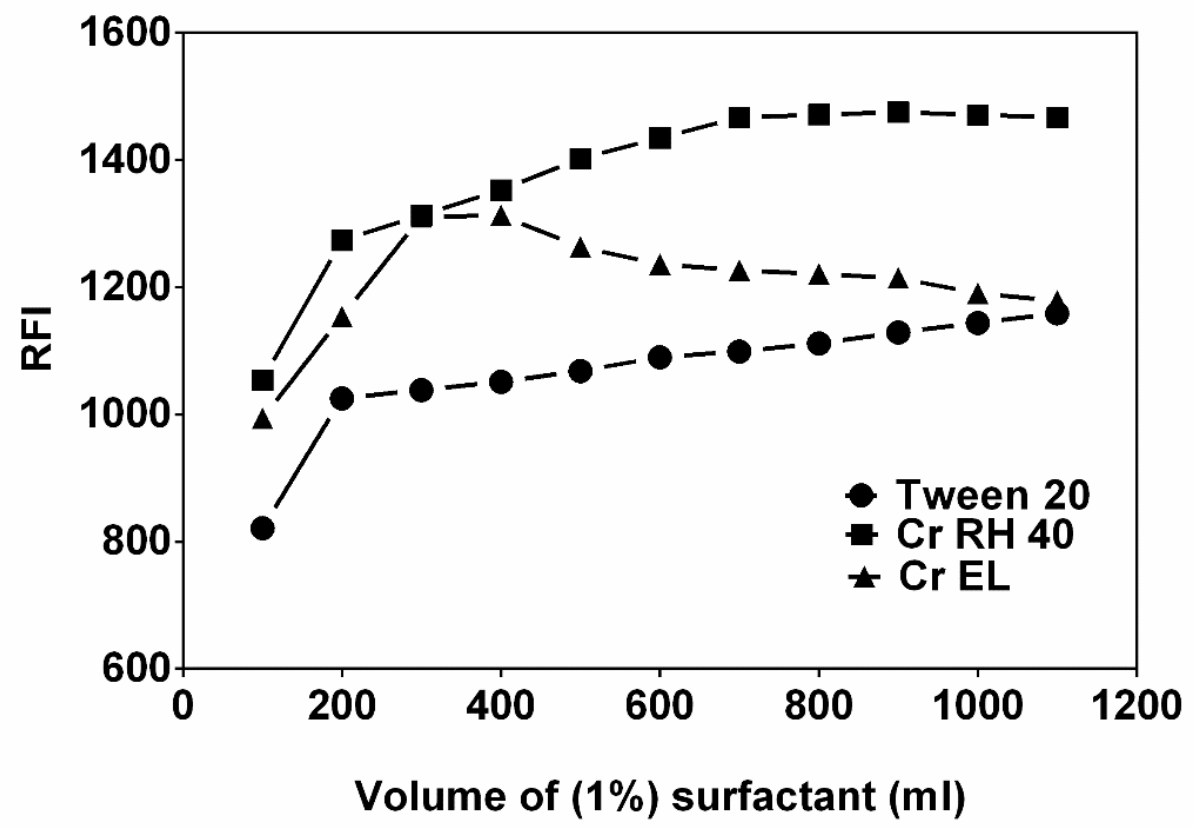

Figure 4: Effect of $\mathrm{Cr} \mathrm{RH} 40, \mathrm{Cr} E L$ and Tween 20 volumes ( $1 \% \mathrm{w} / \mathrm{v}$ ) on RFI of AZL (200 ngmL ${ }^{-1}$ ) 


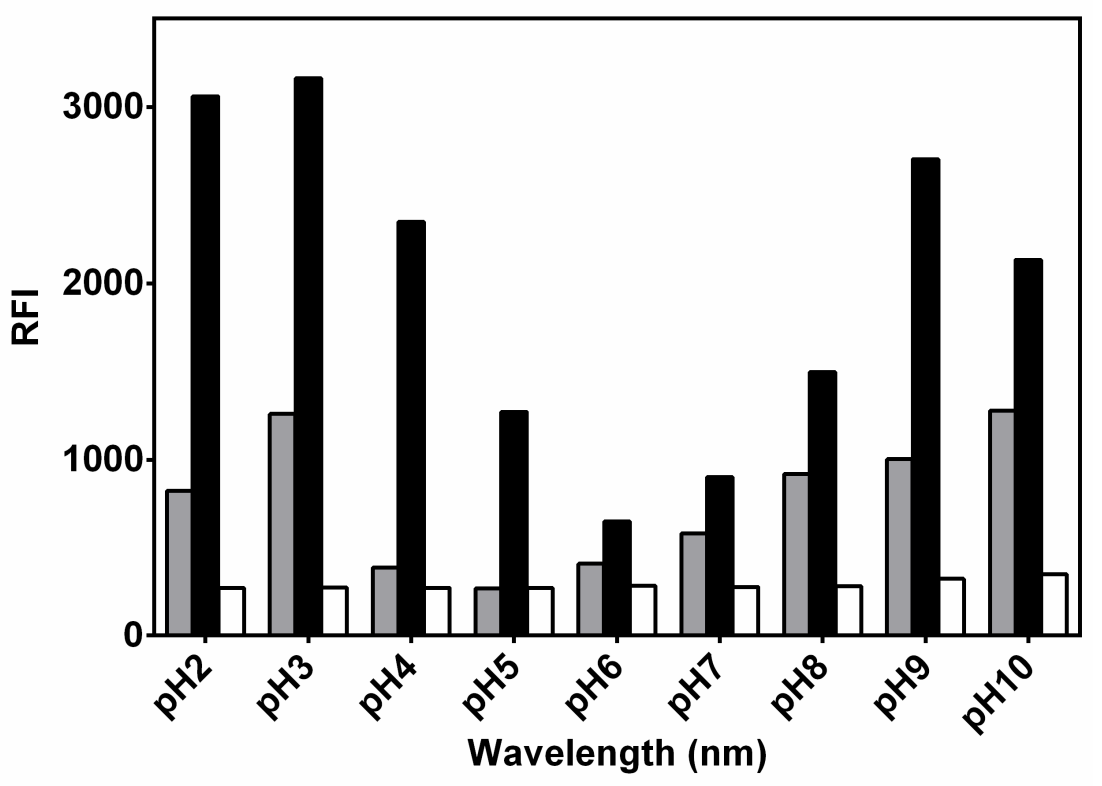

Figure 5: Effect of $\mathrm{pH}$ on the RFI of $400 \mathrm{ngmL}^{-1} \mathrm{AZL}$ in $900 \mu \mathrm{L} 1 \%, w / v \mathrm{Cr} \mathrm{RH} 40$ solution in water (black column AZL with surfactant, gray column AZL without surfactant and white column surfactant only)

\section{Effect of $\mathrm{pH}$}

The $\mathrm{pH}$ of micellar solutions can display significant influence on the degree of solubilization of some compounds, since it may alter the equilibrium between ionized and nonionized form of these compounds [30]. The effect of $\mathrm{pH}$ on RFI of AZL, Cr RH 40 and AZL-Cr $\mathrm{RH} 40$ was examined utilizing different types of buffers covering the whole $\mathrm{pH}$ range, for instance $0.1 \mathrm{M}$ phosphate buffer ( cover $\mathrm{pH}$ range 2-7) and $0.1 \mathrm{M}$ borate buffer (cover $\mathrm{pH}$ range 8-10). Results presented in Figure 5 showed that the optimum $\mathrm{pH}$ value for AZL determination with and without $\mathrm{Cr} \mathrm{RH} 40$ was 3 .

\section{Effect of diluting solvent}

Dilution with various solvents such as water, methanol, ethanol and acetonitrile was employed. Water exhibited the highest RFI compared to the other studied solvents (Fig. 6), this may be due to changing the polarity of the medium which in turn may lead to physical interaction between the solvents and the drug molecules. Therefore, water was chosen as the diluting solvent throughout the study. A reduction in the RFI was detected in the micellar system using methanol, acetonitrile or ethanol. This may be attributed to the denaturation of the micelles by short-chain alcohols such as methanol and ethanol. Furthermore these alcohols may decrease the size of the micelles, and may breakdown the surfactant aggregate at high concentration [31].

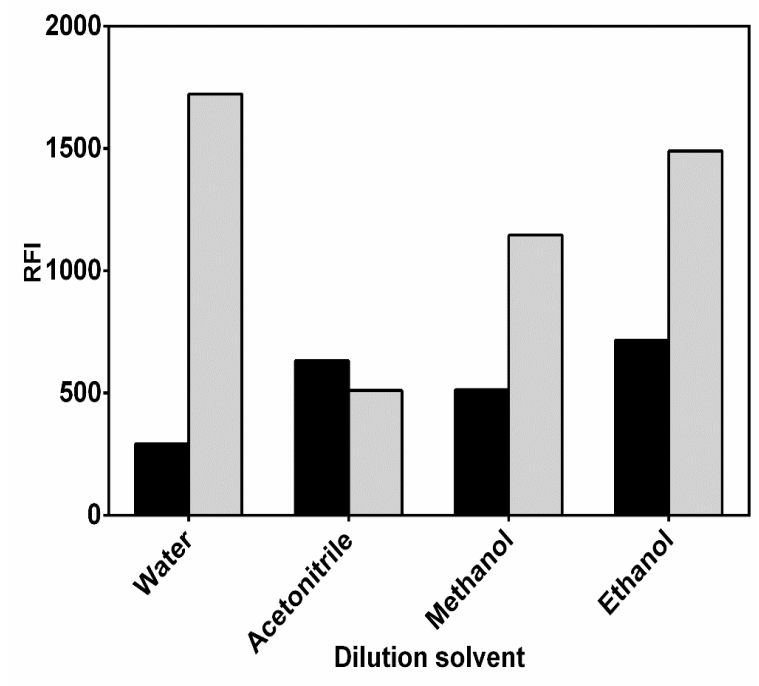

Figure 6: Effect of the diluting solvent on fluorescence intensity of AZL (200 $\left.\mathrm{ngmL}^{-1}\right)$; white column with surfactant and black column without surfactant

\section{Effect of time}

The influence of time on the stability of the RFI of AZL in micellar medium was also studied. It was found that the development of RFI was instanteously and persisted stable for at least one hour.

\section{Validation data}

The proposed methods were validated according to the $\mathrm{ICH}$-guidelines for validation of the analytical procedures [32] in terms of the 
linearity, sensitivity, accuracy, specificity, repeatability and reproducibility

\section{Linearity and range}

The calibration graph for the determination of AZL by the proposed method was constructed by plotting the RFI versus the concentration. The graph was found to be rectilinear over the concentration range 10-500 $\mathrm{ngmL}^{-1}$ (Table 1).

Statistical analysis [33] of the data gave high value of the correlation coefficient ( $r$ ) of the regression equation, small values of; the standard deviation of residuals (Sy/x), intercept $(\mathrm{Sa})$, slope $(\mathrm{Sb})$, the percentage relative standard deviation and the percentage relative error (Table 1). These data proved the linearity of the calibration graph for the studied drug.

Table 1: Analytical performance data for the spectrofluorimetric determination of AZL

\begin{tabular}{|c|c|}
\hline Parameter & AZL \\
\hline Wavelength $\left[\lambda_{\mathrm{ex}} \lambda_{\mathrm{em}}\right](\mathrm{nm})$ & $264 / 371$ \\
\hline Linearity range $(\mathrm{ng} / \mathrm{mL})$ & $10-500$ \\
\hline Intercept (a) & -33.07 \\
\hline Slope (b) & 6.876 \\
\hline Correlation coefficient $(r)$ & 0.9984 \\
\hline S.D. of residuals $\left(S_{y / x}\right)$ & 9.999 \\
\hline S.D. of intercept $\left(S_{a}\right)$ & 6.849 \\
\hline S.D. of slope $\left(S_{b}\right)$ & 0.0293 \\
\hline$\% \mathrm{RSD}^{\mathrm{a}}$ & 1.655 \\
\hline$\%$ Error $^{\mathrm{D}}$ & 0.7435 \\
\hline $\operatorname{LOD}\left(\mathrm{ngmL}^{-1}\right)^{\mathrm{C}}$ & 3.287 \\
\hline $\mathrm{LOQ}\left(\mathrm{ngmL}^{-1}\right)^{\mathrm{a}}$ & 9.961 \\
\hline
\end{tabular}

a Percentage relative standard deviation for three replicate samples; ${ }^{b}$ Percentage relative error for three replicate samples; ${ }^{c}$ Limit of detection; ${ }^{d}$ Limit of quantitation

\section{Limits of quantitation (LOQ) and of detection (LOD)}

Limit of quantitation (LOQ) and limit of detection (LOD) were calculated in accordance with the ICH Q2 (R1) recommendation [32]. LOQ was determined by establishing the lowest concentration that can be measured below which the calibration graph is nonlinear. LOD was determined by evaluating the lowest concentration of the drug that can be detected. The results are also presented in Table 1. The values of $L O Q$ and $L O D$ were calculated according to the following equations:

$\operatorname{LOD}=3.3 \sigma / \mathrm{S}(1)$

$\mathrm{LOQ}=10 \sigma / \mathrm{S}(2)$
Where, $\sigma$ was the standard deviation of the intercept of regression line and $S$ was the slope of regression line of the calibration curve. The results are given in Table 1.

The reported data in the literature supported that our LOQ (9.961 $\mathrm{ngmL}^{-1}$ ) is much lower than maximum plasma concentration $\left(\mathrm{C}_{\max }\right)$ and hence can easily quantify AZL in plasma (reported $C_{\max }$ of $A Z L$ around $5.7 \mu \mathrm{gmL}^{-1}$ ) [34].

\section{Accuracy and precision}

Accuracy, intra-day and inter-day precisions of the proposed method were determined (anticipated in Tables 2 and 3). Three replicate samples in the same day, as well as on three consecutive days were analyzed for intra-day and inter-day precision at different concentrations. Accuracy was calculated as \% bias using the following equation,

$\operatorname{Bias}(\%)=[(\mathrm{A}-\mathrm{B}) \times 100] / \mathrm{A}$.

where $A$ is nominal $A Z L$ concentration, and $B$ the measured AZL concentration.

Bias ranged from -3.05 to $0.2 \%$, thus indicating the high accuracy of the method. The intra-day and inter-day precisions were expressed as recovery $(\% \pm \mathrm{RSD})$. The average recovery percentages (around $100 \%$ ) and the low relative standard deviations (RSD) indicated the inter-day and intra-day precisions of the method (Table 3).

\section{Robustness}

Robustness was assessed by testing the susceptibility of measurements to small changes of the analytical conditions. It was found that small differences that may take place during the experimental operation did not significantly change the response (RFI) of the current method. The results are abridged in Table 4.

\section{Application of proposed method to analysis of AZL in human plasma}

The high sensitivity of the proposed method allowed the determination of AZL in spiked human plasma. AZL is orally bioavailable, reaching peak plasma concentration after 3 of administration. The maximum plasma concentration $\left(C_{\max }\right)$ of $A Z L$ is around $5.7 \mu \mathrm{gmL}^{-1}$ following oral dose of $80 \mathrm{mg}$ [34]. Therefore vast dilutions were made to reach the dynamic linear range of the current method. Absolute recoveries of AZL in spiked human plasma samples were calculated from its corresponding regression equation. The results abridged in Table 5 reveal 
that the \% RSD and mean absolute recoveries of AZL in spiked plasma samples are $1.17 \%$ and $90.54 \%$, respectively. The recovery values are better than those reported by Ramakrishna et al. [26] concerning LC with mass detection for determination of AZL and chlorthalidone in human plasma. Relatively high plasma protein binding of AZL (>99 \%) could be responsible for low recovery values (about $91 \%$ ).

Table 2: Accuracy of the spectrofluorimetric method for determination of AZL

\begin{tabular}{lcclllll}
\hline Day & $\begin{array}{c}\text { Actual } \\
\text { conc. } \\
(\mathbf{n g} / \mathbf{m L})\end{array}$ & $\begin{array}{c}\text { Mean } \\
\text { conc. } \\
(\mathbf{n g} / \mathbf{m L})\end{array}$ & $\mathbf{\pm}$ SD & $\begin{array}{c}\% \\
\text { Nominal }\end{array}$ & $\begin{array}{c}\% \\
\text { RSD }\end{array}$ & $\begin{array}{c}\% \\
\text { Bias }\end{array}$ & SEM \\
\hline 1 & 60 & 61.14 & 1.758 & 101.9 & 2.88 & -1.88 & 0.72 \\
2 & 60 & 60.39 & 2.457 & 100.65 & 4.07 & -0.65 & 1.00 \\
3 & 60 & 59.96 & 1.456 & 99.93 & 2.43 & 0.07 & 0.59 \\
1 & 100 & 101.8 & 1.987 & 101.8 & 1.95 & -1.78 & 0.81 \\
2 & 100 & 101.9 & 4.964 & 101.9 & 4.87 & -1.88 & 2.03 \\
3 & 100 & 103.1 & 0.7685 & 103.1 & 0.75 & -3.05 & 0.31 \\
1 & 200 & 204.2 & 3.471 & 102.1 & 0.47 & -2.08 & 1.42 \\
2 & 200 & 200.3 & 0.9455 & 100.15 & 1.7 & -0.15 & 0.39 \\
3 & 200 & 199.6 & 3.036 & 99.8 & 1.52 & 0.2 & 1.24 \\
1 & 400 & 399.7 & 3.469 & 99.93 & 1.3 & 0.08 & 1.42 \\
2 & 400 & 407.6 & 4.662 & 101.9 & 1.14 & -1.88 & 1.90 \\
3 & 400 & 401.9 & 5.222 & 100.48 & 0.87 & -0.47 & 2.13 \\
\hline
\end{tabular}

SEM = standard error of the mean; 1, 2, 3 represents measurements obtained on day 1, day 2 and day 3 respectively ( $n=3$ for each day)

Table 3: Intra-assay and inter-assay precision and accuracy for determination of AZL by the proposed spectrofluorimetric method

\begin{tabular}{|c|c|c|c|c|}
\hline \multirow{2}{*}{$\begin{array}{l}\text { Nominal } \\
\text { conc. } \\
\text { (ng/mL) }\end{array}$} & \multicolumn{2}{|c|}{ Intra-assay } & \multicolumn{2}{|c|}{ Inter-assay } \\
\hline & $\begin{array}{c}\text { Measured conc. } \\
(\mathrm{ng} / \mathrm{mL})\end{array}$ & $\begin{array}{c}\text { Recovery }(\% \pm \\
\text { RSD) }{ }^{a}\end{array}$ & $\begin{array}{l}\text { Measured conc. } \\
\text { (ng/mL) }\end{array}$ & $\begin{array}{c}\text { Recovery (\% }(\% \\
\text { RSD) }\end{array}$ \\
\hline 60 & 61.52 & $102.53 \pm 2.37$ & 60.5 & $100.83 \pm 0.99$ \\
\hline 100 & 80.94 & $101.18 \pm 1.77$ & 102.27 & $102.27 \pm 0.71$ \\
\hline 200 & 101.03 & $101.03 \pm 1.29$ & 201.37 & $100.68 \pm 1.23$ \\
\hline 400 & 200.24 & $100.12 \pm 0.61$ & 403.07 & $100.77 \pm 1.01$ \\
\hline
\end{tabular}

${ }^{\mathrm{a}}$ Mean of three determinations

Table 5: Results of the determination of AZL in pure form and plasma samples

\begin{tabular}{lllccc}
\hline \multirow{2}{*}{ Parameter } & \multicolumn{2}{c}{ Pure form } & \multicolumn{3}{c}{ Plasma sample } \\
\cline { 2 - 6 } & $\begin{array}{c}\text { Amount taken } \\
\left(\mathrm{ngmL}^{-1}\right)\end{array}$ & $\%$ Found & $\begin{array}{c}\text { Amount } \\
\text { added } \\
\left(\mathbf{n g m L}^{-1}\right)\end{array}$ & $\begin{array}{c}\text { Amount } \\
\text { found } \\
\left(\mathbf{n g m L}^{-1}\right)\end{array}$ & $\begin{array}{c}\% \\
\text { Found }\end{array}$ \\
\cline { 2 - 6 } & 60 & 102.53 & 112 & 99.69 & 89.01 \\
& 80 & 101.18 & 128 & 116.51 & 91.02 \\
& 100 & 101.03 & 144 & 130.12 & 90.36 \\
\hline Mean & 200 & 100.12 & 160 & 146.83 & 91.77 \\
\hline SD & & 101.22 & & & 90.54 \\
\hline
\end{tabular}

\section{DISCUSSION}

Azilsartan (AZL) possesses weak native fluorescence in aqueous medium. Hence, we intended to enhance this emission band, in order to develop a new and sensitive method for the analysis of $A Z L$ in plasma. It became known that adding a surfactant at a concentration greater than its critical micellar concentration to a given fluorophore solution increases the molar absorptivity and/or the fluorescence quantum yield of the fluorophore in many circumstances $[7,35]$. This fact has been used to increase the performance of spectrofluorimetric methods of various analytes. The fluorescence behaviour of $A Z L$ in various micellar media was studied and there was an enhancement about $300 \%$ of the $\mathrm{RFI}$ in the presence of $\mathrm{Cr} \mathrm{RH} 40$ system under the optimum above mentioned conditions. 
Table 4: Robustness of the proposed spectrofluorimetric method

\begin{tabular}{|c|c|}
\hline Variable & Recovery $\pm S D{ }^{a}(\%)$ \\
\hline No variation $^{b}$ & $100.62 \pm 0.18$ \\
\hline \multicolumn{2}{|c|}{ Cr RH 40 volume } \\
\hline 870 & $99.27 \pm 2.11$ \\
\hline 930 & $102.74 \pm .59$ \\
\hline \multicolumn{2}{|l|}{ pH } \\
\hline 3.3 & $98.65 \pm 0.50$ \\
\hline 2.7 & $106.63 \pm 0.13$ \\
\hline \multicolumn{2}{|c|}{ Buffer volume $(\mu L)$} \\
\hline 0.95 & $104.87 \pm 0.39$ \\
\hline 1.05 & $103.43 \pm 0.26$ \\
\hline \multicolumn{2}{|c|}{ Temperature $\left({ }^{\circ} \mathrm{C}\right)$} \\
\hline 20 & $106.93 \pm 0.08$ \\
\hline 30 & $93.17 \pm 0.75$ \\
\hline
\end{tabular}

For exploring whether the enhancement of AZL fluorescence was due to rise in quantum yield or due to increment of absorbance of AZL at $\lambda_{\text {ex }}$; the molar absorptivity of AZL in $\mathrm{Cr} \mathrm{RH} 40\left(\varepsilon_{\text {micellar }}\right)$ was calculated at $264 \mathrm{~nm}\left(\lambda_{\text {ex }}\right)$. The $\varepsilon_{\text {micellar }} / \varepsilon_{\text {acetonitrile }}$ ratio was unity which indicated that the increase in sensitivity is not affected by an increase in the absorption of the drug in micellar system at its $\lambda_{\text {ex }}$. The increase in the quantum yield of $\mathrm{AZL}$ in $\mathrm{Cr} \mathrm{RH} 40$ was produced by protection of the lowest excited singlet state from non-radiative processes in the micellar system. The quantum yield of AZL was found to be 0.249 in methanol and 0.628 in the presence of $\mathrm{Cr} \mathrm{RH} 40$. The quantum yield was calculated according to the following equation [36]:

$\varnothing d=\varnothing q(F d / F q) \cdot(A q / A d)$

where $\varnothing d$ and $\varnothing q$ referred to the fluorescence quantum yields of $A Z L$ and quinine, respectively; $\mathrm{Fd}$ and $\mathrm{Fq}$ represent the integral fluorescence intensities of AZL and quinine, respectively; Ad and $\mathrm{Aq}$ referred to the values of absorbance of the drug and quinine at the excitation wavelength, respectively. The concentration was selected so that the absorbance was less than 0.05 to reduce the error arising from the inner effect [37].

\section{CONCLUSION}

A simple and sensitive spectrofluorimetric method was developed for the determination of AZL through enhancement of its native fluorescence. The suggested method is simple, less time consuming and does not require the elaborate treatment associated with chromatographic methods; moreover, it is sensitive and no need for derivatization reaction. By virtue of its simplicity, rapidity and sensitivity, the proposed method can be applied for the analysis of the AZL in spiked human plasma.

\section{ACKNOWLEDGEMENT}

The authors would like to extend their sincere appreciation to the Deanship of Scientific Research at the King Saud University for funding this work through the Research Group Project no. RGP-322.

\section{CONFLICT OF INTEREST}

No conflict of interest associated with this work.

\section{CONTRIBUTION OF AUTHORS}

We declare that this work was done by the authors named in this article and all liabilities pertaining to claims relating to the content of this article will be borne by the authors.

\section{REFERENCES}

1. Lloyd-Jones D, Adams RJ, Brown TM, Carnethon M, Dai $S$, De Simone G, Ferguson TB, Ford E, Furie $K$, Gillespie C. Heart disease and stroke statistics-2010 update $A$ report from the American Heart Association. Circulation 2010; 121(7): e46-e215.

2. Bakris $G L$, Sica $D$, Weber $M$, White WB, Roberts $A$, Perez A, Cao C, Kupfer $S$. The Comparative Effects of Azilsartan Medoxomil and Olmesartan on Ambulatory and Clinic Blood Pressure. J Clin Hypertens. 2011; 13(2): 81-88.

3. Elliott WJ, Plauschinat CA, Skrepnek GH, Gause D. Persistence, adherence, and risk of discontinuation associated with commonly prescribed antihypertensive drug monotherapies. J Am Board Fam Med. 2007; 20(1): 72-80.

4. U.S. Food and Drug Administration (FDA). Azilsartan medoxomil. In: Center for drug evaluation and Research, editor. MD, USA; 25th February 2011.

5. Kaur K, Saini SS, Malik AK, Singh B. Micelle enhanced and terbium sensitized spectrofluorimetric determination of danofloxacin in milk using molecularly imprinted solid phase extraction. Spectrochim Acta A Mol Biomol Spectrosc. 2012; 96: 790-795.

6. Ocana JA, Barragan FJ, Callejon M. Spectrofluorimetric and micelle-enhanced spectrofluorimetric determination of gatifloxacin in human urine and serum. J Pharm Biomed Anal. 2005; 37(2): 327-332.

7. Walash MI, Belal F, Tolba MM, Halawa MI. Micelleenhanced spectrofluorimetric determination of 
amlexanox in bioadhesive buccal tablets: application to content uniformity testing. Luminescence 2015; 30(6): 823-829.

8. Alarfaj NA, El-Tohamy MF. Determination of the antiviral drug Ribavirin in dosage forms via micelle enhanced spectrofluorimetric method. Luminescence 2013; 28(2): 190-194.

9. Ghasemi JB, Zolfonoun E. Application of principal component analysis-multivariate adaptive regression splines for the simultaneous spectrofluorimetric determination of dialkyltins in micellar media. Spectrochim Acta A Mol Biomol Spectrosc. 2013; 115 : 357-363.

10. Hanguo H, Xiaoxia G, Yan L, Sengtie L. Fluorometric Determination of Trace Amounts of Samarium end Europium in Geological Samples with Thenoyltrifluoroacetone-ophenanthroline Tween 20 Micellar System. Anal Lab. 1987; 9: 6-11.

11. Maggio RM, Piccirilli GN, Escandar GM. Fluorescence enhancement of carbendazim in the presence of cyclodextrins and micellar media: A reappraisal. Appl Spectrosc. 2005; 59(7): 873-880

12. Nevado JB, Pulgarın JM, Laguna MG. Spectrofluorimetric study of the $\beta$-cyclodextrin: vitamin $K 3$ complex and determination of vitamin $K$ 3. Talanta 2001; 53(5): 951 959.

13. Christiansen A, Backensfeld T, Weitschies W. Effects of non-ionic surfactants on in vitro triglyceride digestion and their susceptibility to digestion by pancreatic enzymes. Eur J Pharm Sci. 2010; 41(2): 376-382.

14. Gandhi S, Mittal P, Pahade A, Rege S. Development and validation of stability indicating hptlc method for estimation of azilsartan medoximil. Inter J Pharm Sci. 2015; 6(1): 224-232.

15. Srinivasan R, Chandra JK, Kumar DR, Kumar ND. Stability indicating RP-HPLC method for determination of azilsartan medoxomil in bulk and its dosage form. Int J Pharm anal res. 2014; 3(4): 445-52.

16. Mantena BP, Rao SV, Appa Rao KC, Ramakrishna K, Srikanth Reddy R. Method Development and Validation for the Determination of Potential Impurities Present in Azilsartan medoxomil Tablets by Reverse Phase-Ultra Performance Liquid Chromatography. Anal Chem Lett. 2014; 4(5-6): 287-301.

17. Gorla $R$, Nagaraju C, Sreenivasulu B, Sreenivas $N$, Korupolu RB. New Simple UV Spectrophotometric Method for Determination of Azilsartan medoxomil in Bulk and Pharmaceutical dosage forms. Int $J$ Res Pharm Biomed Sci. 2013; 4: 1133-1137.

18. Gorla R, Sreenivasulu B, Garaga S, Sreenivas N. A simple and sensitive stability-indicating hptlc assay method for the determination of azilsartan medoxomil. Indo Amer J Pharm Res. 2014; 4(6): 2985-2992.

19. Gong C, Wang J, Sun Y, Ding D, Zhong L, Zhu M, Sun J, Zhang $X$. UPLC-MS/MS for the determination of azilsartan in beagle dog plasma and its application in a pharmacokinetics study. Asian J Pharm Sci. 2015; 10(3): $247-253$
20. Vekariya PP, Joshi HS. Development and validation of RP-HPLC method for azilsartan medoxomil potassium quantitation in human plasma by solid phase extraction procedure. Int Sch Res Notices 2013; 2013: 1-6.

21. Ebeid WM, Elkady EF, El-Zaher AA, El-Bagary RI, Patonay G. Spectrophotometric and Spectrofluorimetric Studies on Azilsartan Medoxomil and Chlorthalidone to Be Utilized in Their Determination in Pharmaceuticals. Anal chem insights 2014; 9: 33-40.

22. Ebeid WM, Elkady EF, El-Zaher AA, El-Bagary RI, Patonay G. Stability-indicating RP-LC method for determination of azilsartan medoxomil and chlorthalidone in pharmaceutical dosage forms: application to degradation kinetics. Anal bioanal chem. 2014; 406(26): 6701-6712.

23. Kasimala MB, Kasimala BB. Reverse phase-HPLC method development and validation for the simultaneous estimation of azilsartan medoxomil and chlorthalidone in pharmaceutical dosage forms. J Atoms Mol. 2012; 2(1): 117-126.

24. Naazneen S, Sridevi A. Stability-indicating RP-HPLC method for the simultaneous estimation of azilsartan medoxomil and chlorthalidone in solid dosage forms. Int J Pharm Pharm Sci. 2014; 6(6): 226-243.

25. Sravani $P$, Rubesh Kumar S, Duganath N, Devanna $N$. Method Development and Validation for the Simultaneous Estimation of Azilsartan and Chlorthalidone by RP-HPLC in Pharmaceutical Dosage Form. Int J Pharm Sci. 2014; 4(5): 725-729.

26. Ramakrishna R, kumar Puttrevu S, Bhateria M, Bala V, Sharma VL, Bhatta RS. Simultaneous determination of azilsartan and chlorthalidone in rat and human plasma by liquid chromatography-electrospray tandem mass spectrometry. J Chromatogr B 2015; 990: 185-197.

27. El-Enany NM, El-Sherbiny DT, Abdelal AA, Belal FF. Validated spectrofluorimetric method for the determination of lamotrigine in tablets and human plasma through derivatization with o-phthalaldehyde. J Fluoresc. 2010; 20(2): 463-472.

28. Mandal B, Balabathula $P$, Mittal N, Wood GC, Bhattacharjee $H$. Development and validation of a spectrofluorimetric method for the determination of erlotinib in spiked human plasma. J Fluoresc. 2012; 22(6): 1425-1429.

29. El-Sayed FAL, Mohamed TA, Taha AE. Spectrofluorimetric determination of carvedilol in dosage form and spiked human plasma through derivatization with 1-dimethylaminonaphthalene-5-sulphonyl chloride. Chem. Ind. Chem. Eng. Q. 2010; 16(1): 31-38.

30. Rangel-Yagui CO, Pessoa Jr A, Tavares LC. Micellar solubilization of drugs. J Pharm Pharm Sci. 2005; 8(2): 147-163.

31. Leung R, Shah DO. Dynamic properties of micellar solutions: I. Effects of short-chain alcohols and polymers on micellar stability. J Colloid Interface Sci. 1986; 113(2): 484-499.

32. ICH. Validation of Analytical procedures. Methodology (Q2AR1), International Conference on Harmonization; 
November 1996 and November 2005; USA:: Food and Drug Administration; November 1996 and November 2005.

33. Miller JN, Miller JC. Statistics and chemometrics for analytical chemistry: Pearson Education; 2005.

34. European Medicines Agnecy (EMA). Azilsartan medoxomil, Edarbi Assesment report. London, UK 2011.

35. Darwish HW, Abdelhameed AS, Bakheit AH, Alanazi AM. $A$ new method to determine the new C-Met inhibitor
"Cabozantinib" in dosage form and human plasma via micelle-enhanced spectrofluorimetry. RSC Adv. 2015; 5(51): 40484-40490.

36. Tang B, Wang X, Jia B, Niu J, Wei Y, Chen Z, Wang $Y$. Simple, rapid, and sensitive spectrofluorimetric determination of Zaleplon in micellar medium. Anal lett. 2003; 36(14): 2985-2997.

37. Lakowicz JR. Principles of fluorescence spectroscopy: Springer Science \& Business Media; 2007. 